\title{
REDES DE INTERDEPENDÊNCIA COMO MÉDIUM DECISIVO DO PROCESSO EDUCATIVO
}

\author{
NETWORKS OF INTERDEPENDENCE AS A DECISIVE MEDIUM \\ OF THE EDUCATIONAL PROCESS
}

\author{
RELACIONES DE INTERDEPENDENCIA COMO MEDIO \\ DECISIVO DEL PROCESO EDUCATIVO
}

\author{
Benedito Dielcio Moreira ${ }^{\mathrm{I}}$ \\ Deodato Rafael Libanio de Paula ${ }^{\mathrm{I}}$
}

Resumo Apresentamos neste artigo a concepção de Norbert Elias de que as pessoas mantêm umas com as outras relações de interdependência, mostram-se como indivíduos singulares, únicos, mas fazem parte de teias de relações em que, ao tempo que as constituem como os demais entrelaçados, delas se nutrem, de um modo que nessa modernidade a individualidade se expande, avança para outros universos distantes e globalizados, porém sempre tecendo redes, instituindo novas interdependências. A partir da experiência de realização de vários projetos de pesquisa e intervenção em escolas públicas, com atividades na interface da Educação e Comunicação, foi possível identificar diferentes teias sendo tecidas, todavia, todas elas de algum modo assombradas pela falta de algum tipo de reconhecimento, como mostrou Elias em suas obras, O Processo Civilizador, Os Alemães, Sociedade dos Indivíduos e Mozart. Neste texto, com o apoio do pensamento crítico de Axel Honneth, procuramos destacar a importância das ideias de Elias para uma reflexão contemporânea e crítica sobre o sistema escolar, neste incluído não apenas a comunidade escolar (secretarias de educação, professores, alunos e seus familiares), mas também toda a sociedade.

Palavras-chave: Educação; Norbert Elias; Comunidade Escolar; Reconhecimento Social.

Abstract In this study, we present Norbert Elias' concept that people maintain with each other relations of interdependence, they present themselves as singular, unique individuals; but they belong to a web of relations in which from it feeds itself in the same time it is

I Universidade Federal de Mato Grosso (UFMT). Cuiabá/MT- Brasil. 
constituted as the others interlaced, in a way that the individuality expands, advances to other distant and globalized universes in this modernity, nevertheless always weaving webs, instituting new interdependencies. From the experience of performing several research projects and intervention in public schools, with activities in the Education and Communication interface, it was possible to identify different webs being weaved, however all of them in some way were haunted by the lack of any kind of recognition, as Elias showed in his literatures, The Civilizing Process, The Germans, Society of Individuals and Mozart. In this text, with the support of Axel Honneth's critical thought, we seeked to highlight the importance of Elias' ideas to a contemporaneous and critical reflection about the scholar system, including not only the scholar community (secretaries of education, teachers, students and their families) but also all society.

Key-words: Education; Norbert Elias; School Community; Social Recognition.

Resumen Presentamos en este artículo la concepción de Norbert Elias de que las personas mantienen unas con las otras relaciones de interdependencia, que muestran como los individuos, seres singulares y únicos hacen parte de una tela de relaciones en que, a lo mismo tiempo que las constituyen con los demás individuos enlazados, también si nutren de ella, de un modo que en esta modernidad la individualidad si expande, avanza para otros universos lejos y globalizados, pero siempre tejiendo las telas, instituyendo nuevas interdependencias. A partir de la experiencia de realizaciones de diversos proyectos de investigación e intervención en escuelas públicas, con actividades en la interface Educación y Comunicación, fue posible la identificación de distintas telas siendo tejidas, todavía todas ellas de algún modo asombradas pela falta de un tipo de reconocimiento, como ha mostrado Elias en sus obras, El Proceso de Civilización, Los Alemanes, La Sociedad de los Individuos y Mozart. En este texto, con lo apoyo del pensamiento crítico de Axel Honneth, buscamos destacar a la importancia de las ideas de Elias para una reflexión contemporánea y crítica sobre lo sistema escolar, en este incluso no solo la comunidad escolar (secretarias de educación, profesores, estudiantes y sus familiares), pero también toda la sociedad.

Palabras clave: Educación; Norbert Elias, Comunidad Escolar; Reconocimiento Social.

\section{INTRODUÇão}

Se há uma área do conhecimento cuja abundância de informações e de intervenções de outras áreas se avolumam e se inter-relacionam, essa área é a da Educação. E não é para menos, afinal a Educação está no nascedouro da humanidade, no centro de seu desenvolvimento e qualquer aposta de futuro, seja ela no universo individual, familiar ou de toda uma comunidade, passa necessariamente pela compreensão da Educação em seu sentido lato, de sua história, e de seu atual estágio em seu sentido stricto, formal, assim como o status adquirido e assumido em relação ao próprio sentido atribuído à Educação pela sociedade. E se olharmos para o Brasil de hoje, apesar do esforço descomunal de educadores da educação básica, de formadores nas universidades e dos milhares de papers, teses, disserta- 
ções e monografias temos a sensação de um processo educacional que ao tempo em que se "espiraliza", retorna sobre si mesmo, como que "desespiralizando-se", voltando sempre ao começo em um eterno percurso de idas e vindas.

Esse movimento de seguir em frente e parecer sempre retornar de onde saiu tanto esconde avanços excepcionais obtidos em diferentes experiências, como ressalta uma mesmice modorrenta, que vemos lentamente passar diante de nossos olhos, certos de que cedo ou tarde, em algum momento, irá retornar e ser como já foi. Se, por um lado, há muito avanços, experiências bem-sucedidas, professores altruístas decididamente envolvidos no seu compromisso com a formação dos alunos, por outro convivemos com o analfabetismo funcional, precarização do Ensino Público, evasão escolar, prédios inadequados para o exercício do ensino e da aprendizagem, ausência de uma política centrada no processo educacional e um modelo punitivo e de falta de reconhecimento do valor e da importância da comunidade escolar na formação dos futuros gestores do país.

Este texto tem como propósito, à luz do pensamento de Norbert Elias, principalmente, discutir essas idas e vindas, como se esconde aquilo que deveria estar visível, e como os inúmeros exemplos bem-sucedidos de alunos exemplares, sobretudo no Ensino Público, aparecem até com certa frequência, mas desaparecem nas nuvens de incertezas, descrenças e de ausência de perspectivas futuras. Assim como há um Neymar no futebol, há milhares de jovens correndo dia a dia atrás da bola para dele se aproximar (do que ele representa como craque, como celebridade, como milionário), espaço ocupado por poucos em diferentes agremiações, contra a imensa maioria de invisíveis jovens desportistas esperançosos. $\mathrm{Na}$ educação, quando desponta um grande jovem craque em matemática, em ciências, em língua portuguesa, logo desaparece, com pouquíssimos vestígios de sua trajetória. Assim acontece com a aluna premiada pela ONU, com o ganhador das olimpíadas de Matemática, com o autor de um projeto extraordinário em biologia, em ciências ou em qualquer área. Esses casos são tratados como gênios, indivíduos raros, um "Mozart" da educação, nascido para vencer, desconhecendo que são as redes, as conexões que nos envolvem, o campo de relações, de poder e de oportunidades, em seu conjunto e dinâmica, que somente podem ser compreendidos pela interdependência de fatores presentes em cada um de nós.

A lógica desenvolvida pelo sociólogo Norbert Elias transforma o modode se pensar a sociedade. Indo na contramão das ideias que colocam a sociedade e o indivíduo como elementos análogos, Elias busca o todo. Para este autor, a sociedade não é superior ou mais importante do que o indivíduo. Elias (1994; 2008) defende que a interdependência entre os indivíduos é o elemento chave para se compreender a sociedade. Esse "conceito" é fundamental, pois ele não enrijece a sociedade com um conceito "duro", o que anularia a sua dinâmica e a sua constante transformação sócio-histórica (ELIAS, 1994, p. 15, 16). Por sua vez, essa interdependência revela no caso da educação certo paradoxo. Profissionais da Educação, alunos e sociedade estão juntos, ao mesmo tempo separados por uma "distância espacial" ínfima, quase que inexistente, afinal a escola está erguida na própria comunidade, mas infelizmente cercada por muros, valores e crenças em seu próprio papel, e uma "distância social" extraordinária pelos estereótipos de aluno de escola pública, professor sem 
perspectivas de futuro como educador e sem reconhecimento social pelo esforço e importância de seu trabalho. Assim como mostra Elias em sua obra "SSociologia de um gênio", ao reconstruir a história de Mozart, as distâncias entre os senhores da corte e os serviçais. "A distância social era imensa, mas a distância espacial, muito pequena" (1995, p. 21).

As reflexões neste texto estão centradas na experiência de convivência com diferentes tipos de escolas e localidades desde 2004, desenvolvendo pesquisas na interface da comunicação e educação, com projetos de intervenção e pesquisa, sendo o último deles "Educomunicação, Ciência e Outros Saberes: um estudo do trabalho colaborativo e compartilhável em narrativas transmídias, ${ }^{1}$ uma espécie de síntese das cinco experiências anteriores. Nesse projeto, durante seis meses, em 2015, e mais seis meses em 2016, foram visitadas semanalmente nove escolas da rede Estadual de Ensino em Mato Grosso. O percurso deste artigo começa com uma discussão sobre o pensamento de Norbert Elias, recorre depois à ideia de reconhecimento desenvolvida por Axel Honneth e busca, a partir da experiência dos projetos desenvolvidos, demonstrar o quanto a compreensão do pensamento de Elias pode ser decisiva para a formação de uma cidade educadora.

\section{O pensamento de Norbert Elias}

Elias discute a relação entre sociedade e indivíduo dialogando com Aristóteles. O filósofo grego traz uma alegoria em sua obra da "Casa e das Pedras", que Elias lança mão para discutir a ideia de que a sociedade avança em direções muitas vezes não desejadas pelos indivíduos. Para ele, uma casa não é feita por uma acumulação de pedras, ou seja, não é possível a compreensão do significado de uma casa pelo entendimento de uma pedra isolada. Uma casa jamais pode ser determinada pela pedra que a compõe, porque uma única pedra não determina a colocação e a estrutura da casa, porém ela serve de sustentação para outras pedras que, conjuntamente, sustentam a estrutura, constituindo-a. Desse modo, as pedras representam os indivíduos e a casa a sociedade. Nas palavras de Norbert Elias (1994, p. 16), "as relações de unidades de menor magnitude [...] dão origem a uma unidade de potência maior, que não pode ser compreendida quando suas partes são consideradas em isolamento, independentes de suas relações".

A partir dessa ideia, o autor constrói a proposição de que a sociedade é composta pelas relações de interdependência entre os indivíduos, de tal modo que as suas múltiplas ações sociais compõem um campo, o social, que se relaciona com outros campos, formando uma espécie de "rede" de interdependência. Um contexto muito simples de uma dada sociedade arregimenta um número incontável de pessoas, de empresas e de instituições por exemplo, o modo que um trabalhador compra os alimentos básicos para a sua sobrevivência e de sua

1 Segundo Jenkins (2008), transmídia é uma narrativa midiática que perpassa por diversos tipos de mídia, gerando um engajamento do consumidor, que para compreender a História acaba consumindo diversos produtos de mídias específicas sobre a mesma temática. Nesse processo, o consumo de uma única mídia não gera um entendimento satisfatório sobre a narrativa, pois cada mídia é explorada pelo produtor da melhor maneira possível, atuando de forma sinérgica em relação às outras mídias. 
família. Essa rotineira ação de passar no supermercado envolve inúmeros contextos do processo produtivo, como a produção de grãos, produção de carnes, industrialização de produtos, além da prestação de serviços diversos, mercado financeiro, convocando ainda uma política de industrialização, controle inflacionário, geração de impostos e espaços de poder político, entre outros, tanto no campo como nas cidades. Assim, um simples ato de consumo envolve toda a cadeia produtiva, requer para garantir a existência dessa prática a atuação de milhares de indivíduos, empresas, governos e instituições em um processo de total interdependência, por meio da qual se constitui, segundo Elias, o que chamamos de sociedade.

O autor propõe a "alegoria da rede", de tecido, para explicar os processos de interdependência. Em uma rede, os fios estão ligados uns aos outros, compondo algo que não existiria sem essa interconexão. Porém, a totalidade da rede e a forma que cada fio assume não podem ser compreendidas de modo isolado, pois a rede só pode ser compreendida se for analisada à maneira que os fios se ligam, em sua relação de reciprocidade e dependência. Essas relações compõem um sistema de "tensões" em que cada fio da rede concorre com os demais; cada fio, ao seu modo, conforma o seu lugar, a sua dimensão e função na rede. Além disso, cada alteração na rede modifica a composição de cada fio que a constitui, o que não muda a singularidade e a necessidade da interdependência entre os fios.

Acerca dessa metáfora de rede, o autor ressalta que se trata apenas de uma imagem, e como toda a imagem é rígida e de certa forma inadequada, pois a rede é algo estático, e a sociedade não é, de modo que a imagem mais próxima da ideia de sociedade seria uma rede sempre inacabada, com um contínuo tecer e destecer de fios (ELIAS, 1994, p. 35). Essa ideia de constante movimento, sempre em busca de uma forma sem jamais dela apropriar-se, está também presente em outros autores. Para Geertz (1989), por exemplo, as estruturas conceituais de uma sociedade estão "sobrepostas ou amarradas umas às outras", o que requer do interpretante o esforço de compreensão de como estão socialmente construídas as "teias de significados" manifestas nos comportamentos coletivos e individuais. Em Vygotsky (2001; 2002), reside na interação e na convivência social a construção do ser humano, o que significa dizer que sem o outro ser humano algum conseguiria sobreviver. Mais ainda: além dos cuidados primários para a sobrevivência, o ser humano nasce no interior de um grupo já existente (ELIAS, 1994; 2008), aos cujos integrantes cabem a tarefa de cuidar de seu desenvolvimento físico, afetivo, de seus valores, sistema de crenças e de convivência social. Assim como descreve Leontiev, (2004, p. 285): "Podemos dizer que cada indivíduo aprende a ser um homem. $\mathrm{O}$ que a natureza lhe dá quando nasce não the basta para viver em sociedade. É-lhe ainda preciso adquirir o que foi alcançado no decurso do desenvolvimento histórico da sociedade humana".

Voltando a Elias, esse movimento de "tecer e destecer" ocorre porque cada indivíduo vive em uma "malha" de relações móveis, cuja potência gerada nessas relações "retorna" a ele, e é isso o que compõe a individualidade na "estrutura". Em cada associação de seres humanos, o contexto tanto de um indivíduo quanto de um conjunto de indivíduos possui uma "estrutura muito específica" (ELIAS, 1994, p. 22). Nessa perspectiva, cada função social existe porque ocupa um lugar na rede e porque se comunica com outros locais, que acabam designando-lhe a sua função e o seu espaço. 
atos de muitos indivíduos distintos, especialmente numa sociedade tão complexa quanto a nossa, precisam vincular-se ininterruptamente, formando longas cadeias de atos, para que as ações de cada indivíduo cumpram suas finalidades. Assim, cada pessoa singular está realmente presa; está presa por viver em permanente dependência funcional de outras; ela é um elo nas cadeias que ligam outras pessoas, assim como todas as demais, direta ou indiretamente são elos nas cadeias que as prendem. Essas cadeias não são visíveis e tangíveis como grilhões de ferro. São mais elásticas, mais variáveis, mais mutáveis, porém não menos reais, e decerto não menos fortes. E é a essa rede de funções que as pessoas desempenham umas em relação a outras, a ela e nada mais que chamamos "sociedade" (ELIAS, 1994, p. 23).

Não há, portanto, sociedade sem indivíduos e indivíduo sem interdependência. Para Norbert $\operatorname{Elias}^{2}$ (1994), o homem não nasce indivíduo, ele se torna indivíduo na sociedade, ou seja, o indivíduo é um "ser social" que apreendeu leis, normas e regras pelos processos de interdependência com outros indivíduos. Portanto, a sociedade produz o que é de ordem social, como também o que é de ordem individual (ELIAS, 1994, p. 56). Contudo, os espaços relacionais que cada indivíduo ocupa na sociedade são formados por uma série de ligações complexas, por exemplo, a sua renda, o seu emprego, a sua função familiar, a sua descendência, a sua formação escolar etc., características estas que formam um tecido de ligações único que tanto expande em sua rede quanto retorna com todas as atuações dos outros e reverbera em sua formação de indivíduo, diferenciando-o dos outros (ELIAS, 1994, p. 21).

O conjunto complexo de inter-relações em que um indivíduo atua é o que compõe a sua singularidade. É justamente essa "malha" de relações que o envolve mais diretamente que irá coagi-lo, pois esse conjunto de ligações diz respeito a um campo social, com determinadas normas e regras. Assim, o indivíduo equilibra a liberação da libido e as coerções sociais, dada a sua posição dentro da estrutura reticular da sociedade. Esse fenômeno Elias chama de "autorregulação". O que o autor faz aqui é dar novos passos à leitura feita por Freud na obra "O mal-estar da civilização" (2010).

Segundo Freud (2010), a estrutura social constitui-se como instrumento de repressão da libido de cada indivíduo, de modo que cada um passa a se compor como um ser reprimido socialmente. Porém, essa mesma sociedade que reprime também cria mecanismos para a liberação, por exemplo, as festas e as artes. Assim, o indivíduo consegue equilibrar as energias de sua psique, o que torna possível a vida em sociedade. Elias vai absorver essa ideia e dar novos passos, pois para ele cada indivíduo está situado em um local singular da sociedade, em que uma pressão muito específica é exercida sobre ele, de tal modo que as repressões da libido passam a ser muito específicas da função que cada indivíduo tem

2 No entendimento do autor, os indivíduos se relacionam entre si e constroem configurações que formam a sociedade. Em sua obra "Sociologia Fundamental" (2008), ele argumenta que a sociologia deve deixar de centrar-se em elementos conceituais metafísicos, questões a priori, e passar a analisar e sustentar suas ideias a partir das relações construídas pelos indivíduos, considerandoas ações a partir de uma perspectiva compreensiva e descritiva. 
com a estrutura. Outro ponto é que a estrutura também se modifica constantemente, o faz com que o processo de autorregulação também se modifique a cada mudança social. Além disso, esse processo leva em conta a historicidade de cada sujeito, pois os resultados de suas ações desde a infância marcam a formação da sua psique como um "estado" constante de transformação. Então, o que é denominado de individualidade nada mais é do que o conjunto das peculiaridades psíquicas de um sujeito, que revelam as qualidades estruturais de sua autorregulação e, por consequência, apontam para as suas formas de agir (ELIAS, 1994, p. 54).

Devido à sua singularidade na estrutura reticular da sociedade, cada indivíduo possui um campo de ação muito específico, que marca o número de possibilidades de ações que ele pode objetivar. Esse campo de ação marca o conceito de liberdade para Elias, que ele denomina de "margem de escolha". Para o autor, ninguém é absolutamente livre, as pessoas agem conforme as possibilidades surgem para elas em determinado momento ou contexto, que são desdobramentos do "espaço social" que elas ocupam. Esse conceito revela também uma ideia de poder, pois quem possui maior "margem de escolha" tem uma possibilidade maior de executar ações do que pessoas que têm uma margem menor.

Todos esses fatores estão vinculados ao conceito de indivíduo e, como se percebe, o lugar que ele ocupa é determinante para a sua formação e por conseguinte para o seu campo de ação. Desse modo, toda "a maneira como o indivíduo se vê e se conduz em suas relações com os outros depende das estruturas da associação ou associações a respeito das quais ele aprende a dizer "nós"” (ELIAS, 1994, p. 39). Em todos "nós" existe um campo "comum" de inter-relação, que reverbera em cada indivíduo, somando algo em suas características pessoais. Esse Esse algo do "comum" é o que Elias chama de habitus. Esse conceito diz respeito à relação "nós" que cada "eu” possui, pois ao dizer "nós" esse "eu" está compartilhando uma série de hábitos e costumes de determinado grupo. Podemos dizer que o habitus é uma forma de "ser e estar em comum" de determinado grupo, que reverbera em cada "modo de ser" de seus integrantes.

\footnotetext{
Esse habitus, a composição social dos indivíduos, como que constitui o solo de que brotam as características pessoais mediante as quais um indivíduo difere dos outros membros de sua sociedade. Dessa maneira, alguma coisa brota da linguagem comum que o indivíduo compartilha com outros e que é, certamente, um componente do habitus social - um estilo mais ou menos individual, algo que poderia ser chamado de grafia individual inconfundível que brota da escrita social (ELIAS, 1994, p. 150).
}

Pode-se perceber que o "eu" se forma pelo "nós" e o "nós" se forma pela inter-relação entre diversos "eu's". Retomemos aqui um ponto: não é a sociedade que determina o indivíduo e não é o indivíduo que determina a sociedade, ambos se formam por um processo de interdependência. A sociedade nada mais é do que o resultado de ligações complexas de interdependência, em constante transformação (ELIAS, 2008). E é justamente nesse processo de interdependência que o indivíduo se forma. A formação de um "ser social" é 
denominada por Elias como processo de individualização. Esse processo mostra o percurso da criança até a idade adulta. E, por isso, a historicidade de cada indivíduo "é a chave para compreensão do que é a 'sociedade"'(ELIAS, 1994, p. 30).

Além deste ponto, temos que considerar que em cada estágio histórico-social o processo de formação do indivíduo se revela de forma diferente, pois essa formação "depende da evolução histórica do padrão social, da estrutura das relações humanas" (ELIAS, 1994, p. 28). Por isso, em estágios mais avançados da sociedade, a complexidade das relações atua de um modo em que a formação do indivíduo ocorra mais lentamente, o faz com que o tempo para ele se tornar um adulto também seja maior. Segundo Norbert Elias, deve-se considerar que quanto mais complexa e abrangente a sociedade, $\mathrm{e}$

\begin{abstract}
quanto mais intenso e multifacetado é, numa sociedade, o controle dos instintos exigido pelo correto desempenho dos papéis e funções adultos, maior se torna a divergência entre o comportamento dos adultos e das crianças. A remodelação do indivíduo durante o crescimento, o processo civilizador individual em cujo decurso ele se desloca do ponto de partida do comportamento infantil, que é o mesmo em toda parte, para se aproximar mais ou menos do padrão de civilização atingido por sua sociedade, torna-se mais difícil e demorado. Prolonga-se o lapso de tempo necessário para preparar os jovens para os papéis e funções mais complexos do adulto (ELIAS, 1994, p. 104).
\end{abstract}

Essa transformação no processo de formação do indivíduo está vinculada à ideia de processo civilizador. Norbert Elias trabalha com esse esse conceito em uma obra dividida em dois volumes $(1993 ; 2011)$, mostrando como foi o desenvolvimento da sociedade das cortes francesa e alemã até o início da modernidade, apresentando as transformações nos seus hábitos, costumes e, principalmente, na "etiqueta", que eram os hábitos e práticas vistos como nobres ou bem aceitos pela sociedade. Ao analisar esse processo, Elias percebe que o tempo social tem uma caraterística própria, ele não pode ser visto como algo rígido e fixo, mas como um "longo período de duração", o que o fez trabalhar com a ideia de continuum (ELIAS, 1994, p. 43). Essa ideia representa uma progressiva complexificação social em cada estágio da civilização, mostrando que com o desenvolvimento da civilização uma sociedade não se torna mais ou menos civilizada, mas ela se torna mais complexa.

Entre os elementos dessa constante complexificação estão as mudanças na sociedade, que se revelam como uma consequência da interdependência entre os indivíduos. Por isso, se as esferas sociais se modificam, as inter-relações mudam, o que afeta toda a sociedade, o que torna o processo de individualização diferente de tempos em tempos, pois a pressão que a interdependência exerce no indivíduo é diferente em cada configuração.

Uma das características que tornam muito clara essa conexão entre o tamanho e a pressão interna à rede de interdependência, por um lado, e à constituição psicológica do indivíduo, por outro, é o que chamamos de 'ritmos' de nosso tempo. Esse 'ritmo' nada mais é que uma manifestação do grande número de cadeias, entrelaçadas de interdependência, abrangendo todas as funções sociais que os indivíduos têm que desempenhar, e da pressão competitiva que satura essa rede densamente povoada e que afeta, direta ou indiretamente, cada ato isolado da pessoa (ELIAS, 1993, p. 207). 
Como Elias aponta, o ritmo social afeta as ações dos indivíduos, o que o leva a entender a magnitude da importância e do funcionamento dos processos de interdependência. Tanto que um dos conceitos mais importantes da obra eliasiana é o de configuração. Esse conceito discute os "níveis" de interdependência de um estágio de uma sociedade específica, apontado para as diferenças nos processos de autorregulação, individualização, entre outras coisas, comparados a outros estágios da sociedade. Segundo Kirschner (2015, p. 60), o conceito de configuração talvez seja o mais importante da construção teórica de Norbert Elias, porque ele se refere justamente à questão das ligações de interdependência entre os indivíduos. A configuração de uma sociedade apresenta certa característica e pressão nos indivíduos, e também revela uma dinâmica de relações. Porém, ao mesmo tempo em que os indivíduos são influenciados pela configuração, eles também podem transformá-la. Em longo prazo, a configuração surge como uma cristalização cega e não planejada, apresentando um conjunto de ações e características comuns, uma "estrutura" de determinado "tempo" dentro do continuum da civilização.

A ideia de configuração não se limita apenas a grandes grupos de indivíduos, como uma sociedade, um país, mas também a relações de menor escala, como uma escola, por exemplo. No desenrolar das relações surge um habitus, criado pelas próprias pessoas que fazem parte do grupo. E essa configuração, ao mesmo tempo em que é construída pelos indivíduos também atua como uma força que os leva a agir de determinadas formas e não de outras, ou seja, ao mesmo tempo em que a estrutura coage, ela também abre espaços para ser continuamente tecida pelos seus integrantes, a partir de suas vontades e aspirações (ELIAS, 2008, p. 18, 19). Outro ponto é a interferência na configuração de outros grupos, como no caso da escola as intervenções do Estado, de núcleos políticos, dos meios de comunicação, entre outros. ${ }^{3}$

Elias discute que quando os laços entre as pessoas vão se modificando, quer dizer que está havendo uma mudança qualitativa na sociedade:

Cada 'aumento' nas restrições e interdependência era expressão do fato de que os laços entre as pessoas, as maneiras como dependiam uma da outra, estava mudando, e mudando qualitativamente. É isso o que significam diferenças em estrutura social. Com a rede dinâmica de dependências de que se tecia a vida humana, as pulsões e comportamento dos indivíduos assumiam uma forma $d i$ ferente. E é isso o que significam também diferenças em estrutura de personalidade e em padrões sociais de conduta [...] Não quer isso dizer que a direção em que esses processos se desenvolviam fosse no sentido do melhoramento, de 'progresso', ou no rumo oposto, a 'retrogressão'. Mas tampouco quer dizer que envolvessem simplesmente mudanças quantitativas (1993, p. 82, 83).

3 Vale ressaltar que as ligações entre os indivíduos também compõem um campo de poder e de conflito, pois as relações sociais não se constituem em plena harmonia. E o próprio fato de que se modificam ao longo do tempo, mostra como as relações de "tensão" entre os fios que compõem a rede também são partes influentes no processo relacional que Norbert Elias chama de configuração. 
Aqui, neste ponto, para nos auxiliar na reflexão sobre a Educação, sobretudo a formal, escolar, recorremos ao filósofo e sociólogo Axel Honneth, um dos mais expressivos intelectuais da terceira geração da conhecida "Escola de Frankfurt", na qual integram autores do porte de Max Horkheimer, Theodor Adorno, Herbert Marcuse, Jürgen Habermas, entre outros. Primeiramente, é preciso admitir que a ideia de reconhecimento social no Brasil está, em nosso entendimento, mais próxima das questões de aceitação das diferenças, das reivindicações de grupos sociais, ou mesmo de questões mais subjetivas, conforme reflexões do sociólogo Bernard Lahire. ${ }^{4}$ No entanto, é nosso desejo aproximar a ideia de reconhecimento social de Honneth com os conceitos de continuun histórico e de habitus desenvolvidos por Elias e já discutidos, mesmo porque, segundo Honneth (2013, p. 64), as "reflexões sobre o processo de socialização (sozialization) contém a ideia de um entrelaçamento entre individualização e socialização (Vergesellschaftung), que já permite tirar algumas conclusões sobre a importância dos grupos sociais para o amadurecimento individual".

Entende Honneth, em sua discussão sobre o Eu no Nós (Das Ich im Wir), ser justificada a aceitação de "uma necessidade normal, quase natural dos sujeitos, de serem reconhecidos como membros em grupos sociais nos quais eles possam ver confirmadas duradouramente, através de interações diretas, suas necessidades, sua capacidade de julgamento e suas diversas habilidades" (HONNET, 2013, p. 65). O reconhecimento, de acordo com o autor, passa por três aspectos importantes: o amor, o direito e a estima (HONNETH, 2009, p. 24). O amor nada mais é do que uma relação de autoconfiança e confiança recíproca, um fundamento da moralidade, é "o pressuposto psíquico do desenvolvimento de todas as outras atitudes de autorrespeito" (HONNETH, 2009, p. 177), algo vital para a autorrealização. Já a segunda forma de reconhecimento, no universo do direito, a condição para a existência de respeito, tem relação direta com a exclusão, com a injustiça, ou com o "precário acesso à justiça, o que afeta o autorrespeito e moral do indivíduo" (FUHRMANN, 2013, p. 87). Se, por um lado, o direito representa no entendimento de Honneth $(2009$, p. 198) "o medium de reconhecimento que expressa propriedades universais de sujeitos humanos", a estima, ou a solidariedade, tem relação com a aceitação das qualidades, o que leva ao fortalecimento da autoestima.

Após uma rápida passagem pelos três tipos de reconhecimento definidos por Honneth, uma vez que não é propósito deste texto estabelecer uma discussão mais aprofundada dessa dessa teoria, cujo núcleo central é o "Reconhecimento Intersubjetivo e Social" (FUHRMANN, 2013, p. 79), pontuamos que para Honneth um indivíduo é parte de um grupo, de uma sociedade que o ajuda a ser como é, que lhe "dá sentido" (SAAVEDRA; SOBOTTKA, 2008, p. 16). Para Elias, o indivíduo nasce em um grupo já existente e herda não apenas as características físicas e biológicas de seus genitores, mas também os valores, as crenças, o habitus do grupo social. A ideia de interdependência, que se consolida com o conceito de sociedade reticular, pode ser vista como paradigma epistemológico, ajudando a compreen-

\footnotetext{
4 Entrevista de Bernard Lahire concedida à professora Cinara Lerrer Rosenfield e alunos da Universidade Federal do Rio Grande Sul, publicada na revista Sociologias, n. 38, em 2015, no seguinte endereço: http://www.

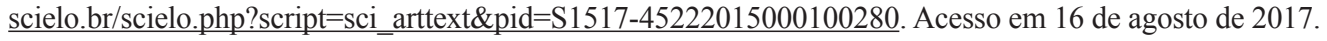


der o funcionamento de determinados locais e contextos. Portanto, a aplicação da ideia de interpendência faz reinterpretar o funcionamento e a formação de uma instituição, como uma escola, por exemplo.

\section{Projeto educomunicaÇão}

O projeto "Educomunicação, Ciência e Outros Saberes: um estudo do trabalho colaborativo em narrativas transmídias" foi desenvolvido pela Universidade Federal de Mato Grosso, com atuação em nove escolas públicas do Ensino Básico do Estado de Mato Grosso, nos anos de 2015 e 2016. As atividades realizadas durante o projeto promovem novas formas de ensino e aprendizagem, introduzindo as tecnologias digitais no processo educativo. Além desse fator, o uso do trabalho colaborativo e de narrativas transmídias são utilizados para estimular os alunos a produzirem conteúdos dentro e fora de sala de aula. $\mathrm{O}$ projeto, em síntese, tem como propósito apresentar novas práticas pedagógicas, não mais unicamente centradas no professor como detentor do saber, no quadro-negro e na sala de aula. As atividades, ao contrário, são estimuladas de forma colaborativa, em formato de projetos, em que professor, um mediador na aquisição de conhecimentos, e aluno se relacionam de forma comum, um aprendendo com o outro, fazendo uso das novas tecnologias e levando a produção e o ensino para fora da sala de aula, estimulando o aluno a se tornar um pesquisador e um produtor de conteúdo, tornando-o autônomo no processo de desenvolvimento intelectual.

Para atingir esse objetivo, são desenvolvidas nas escolas pela equipe do projeto oficinas de fotografia, áudio, audiovisual, trabalho colaborativo, inteligência coletiva, criatividade, narrativas diversas e jornalismo. A execução de todas as atividades requer a participação de alunos e professores, pois essas oficinas fornecem aos seus participantes "ferramentas" básicas para a construção de conteúdos. Os participantes utilizam suas habilidades no manuseio das máquinas, somando-se ao conhecimento discutido em sala de aula e ao conhecimento acumulado, os saberes populares das comunidades em que vivem. Esse conjunto de saberes atua como alavancas para a produção de novos conteúdos, como vídeos educativos, matérias para jornal, áudios, fotografias, entre outros. Sobre essa produção, no ano de 2016 avançamos em relação a 2015, com a produção de narrativas sobre as lendas de cada região, publicação de e-books, álbuns fotográficos e jornais impressos em formato tabloide (antes era em formato A4), com letras maiores, design mais arrojado e com mais facilidade de leitura, de modo a contemplar especialmente os pais dos alunos.

Durante a realização das atividades do projeto, os alunos são divididos em diversos grupos. Em cada um deles há um aluno responsável por uma atividade específica entre as diversas tarefas que cada grupo assume. Por exemplo, um dos integrantes produz textos informativos, ou ficcionais, ou poesias, outro vídeo ou áudio ou fotografias e assim por diante, compondo uma história por meio de diferentes linguagens e plataformas. Além dos alunos, cada grupo conta com a participação de um ou mais professores. As pautas de tra- 
balho no projeto estão vinculadas ao conhecimento escolar e às histórias das comunidades dos alunos. O trabalho está dividido em três eixos: História e Comunidade, Vida e Natureza, Arte e Tecnologia. Esses três eixos permitem a elaboração de uma "pauta multimídia", gerando a partir da criatividade de cada um e do trabalho colaborativo do grupo diversos modelos de narrativa. Os temas das pautas podem ser variados, desde que estejam enquadrados em um dos eixos.

Um dos pontos centrais do projeto é a relação do grupo de pesquisadores com a escola. Em um primeiro momento, procuramos olhar e compreender a vida dos alunos, dos professores e da comunidade, para que pudéssemos nos tornar mais próximos, para pouco a pouco não mais sermos vistos como "estrangeiros". Porém, esse esse é um trabalho delicado, o que fez com que a equipe demorasse um pouco mais para estabelecer um diálogo mais horizontal. As escolas com as quais tivemos mais facilidade para trabalhar foram aquelas cuja aproximação foi mais afetiva e propositiva, com franco envolvimento de todos os professores. Já as dificuldades tanto de aproximação como de execução das atividades colaborativas foram mais expressivas nas escolas maiores, com mais alunos, notadamente urbanas e em grandes cidades. Nessas escolas, o envolvimento com o projeto foi limitado a um grupo de professores, por conta do tamanho da escola e também das inúmeras atividades da maioria do corpo docente.

Durante o projeto, percebeu-se que tirar o celular dos estudantes é o mesmo que tirar algo que faz parte deles, ${ }^{5}$ por isso a ideia de conciliar as tecnologias digitais com as atividades de ensino e aprendizagem. No decorrer das atividades, os jovens passaram a ter um melhor controle técnico das máquinas, possibilitando e capacitando-os para se tornarem autônomos no processo de construção do conhecimento e na produção de conteúdo. ${ }^{6}$ No fim das atividades de 2015 e de 2016, percebeu-se que com o projeto os jovens estavam produzindo com mais autonomia, tornando-se "senhores" de todo o processo, livres para criar e deixar fluir suas capacidades lúdicas.

Entre as nove escolas foi possível observar as diferentes teias tecidas segundo o grau de reconhecimento nas inter-relações com os diversos públicos da comunidade escolar. Enquanto uma escola mais próxima do centro político de decisão e dos líderes sindicais assume com mais proeminência o exercício político do reconhecimento de seus direitos, por sua vez ela estabelece relações mais distantes com os alunos e ainda muito mais distantes com os pais. Já escolas mais distantes, do interior, com pouca expressividade política e acesso precário ao direito de reivindicar direitos e respeito, mantêm uma relação de amizade, de recíproca confiança entre os pares e com os alunos, e com muito mais proximidade com os pais dos jovens.

5 Essa questão foi trabalhada por Libanio (2017) como "empatia maquínica". Nesse texto, ele discute a questão do consumo das mídias e as suas reverberações no social, pela perspectiva do continuum histórico.

6 Moreira discute essa questão em dois momentos. No primeiro momento (MOREIRA 2015), o autor constrói a proposição de que o controle técnico das máquinas potencializa o jovem a utilizá-las para se tornar um produtor de conteúdo, liberando toda a sua capacidade lúdica, mostrando-se autônomo no uso das máquinas e não submisso a elas. No segundo momento (MOREIRA; FICHTNER, 2015), os autores trabalham a questão da capacidade lúdica e inovadora dos jovens com relação ao uso das máquinas para produzir conteúdo. 
Ao olharmos as diferentes escolas pelas lentes de Elias, suas diferentes realidades, não só encontramos singularidades, mas também campos de ação específicos, delimitando escolhas, configurando-se pela inter-relação dos indivíduos e reconfigurando-se tanto no desenvolvimento de suas ações como por força de outros campos que as pressionam. Como exemplo, retomamos o caso das escolas maiores, com mais proximidade com as estruturas de poder (Executivo e Legislativo estaduais, principalmente), enquanto as menores e distantes com mais proximidade com as comunidades do entorno da escola. Os processos de objetivação de escolhas são completamente distintos: enquanto professores de escolas do campo moram nas proximidades das escolas, com poucas chances de outras fontes de renda, dedicando mais tempo aos alunos e pais, os professores urbanos complementam suas rendas com novas salas de aula em outras escolas ou em outras atividades, o que limita tanto o envolvimento mais constante com os alunos e, sobretudo, com a comunidade escolar.

A ideia de "nós" como composição dos vários "eu's" que se formam em cada escola não segue os mesmos caminhos. As configurações dos "nós" nas escolas maiores são distintas entre si e dos "nós" que constituem as escolas menores. De fato, cada escola é formada pelos seus indivíduos, que, por sua vez, são influenciados pela própria estrutura, o que gera um processo de interdependência, ou modos de "ser e estar em comum" em constante movimento. $\mathrm{O}$ envolvimento de gestores e professores das escolas menores com o projeto permitiu uma reconfiguração dos modos de ser, com novos níveis de interdependência e de limites nos processos de autorregulação, como mostra o depoimento a seguir, de uma professora.

O projeto foi muito bom, produtivo, tanto para os professores quanto para os
alunos. Alunos que eram tímidos, que não gostavam de falar, alunos que não
gostavam de produzir, que não tinham relacionamentos muito próximos ao pro-
fessor, e a gente viu isso melhorar muito. A gente sentiu o aluno mais próximo,
a gente também conseguiu se aproximar mais do aluno. Parece que quebrou um
certo tabu. Houve, no social, e isso foi muito bom. A produção, houve muito
elogio. Quando os alunos produziam texto, e depois ter alguém sentado do lado
deles para ajudar na correção, isso foi muito rico (Professora de uma das esco-
las menores. Depoimento gravado em vídeo).

Ainda no interior das escolas, teias de interdependência são tecidas em diferentes "tonalidades" e "qualidade de fios", conforme o princípio e o grau de reciprocidade entre os professores e entre professores e alunos, entre a escola e os pais dos alunos e com a população do entorno, igualmente com diferentes níveis de reconhecimentos afetivos, de respeito e de solidariedade. Cada escola uma cultura, um modo de ser, um habitus, um status, um conjunto de decisões segundo suas margens de escolha. Não encontramos uma escola igual à outra, embora o desejo de acertar, de se mostrar útil, de cumprir o papel pedagógico que lhe é devido encerra uma característica constante e comum a todas elas. A dinâmica das relações estabelecidas entre os profissionais da educação, com diferentes estágios de colaboração e interdisciplinaridade, e com o poder do Estado, mais próximo da punitividade do que da valorização do fazer educacional, estabelece modelos de interdependência, muitas 
vezes centrados no medo, na descrença de transformações à vista, na baixa autoestima, no sentimento de desrespeito e pouca solidariedade por parte da sociedade como um todo.

Por sua vez, as ações colaborativas encontradas em algumas escolas, o alto grau afetivo entre os seus integrantes e o respeito dos pais e da comunidade local para com a importância e a dedicação dos professores mostram-se como potências transformadoras, ricas em inovação e criatividade. As escolas (aqui pensadas enquanto professores, técnicos, gestores locais e alunos) travam, em verdade, com diferentes graus de reconhecimento entre os diferentes públicos, uma luta solitária. Esses jeitos de ser e de fazer educação estão, ao modo de Elias, tanto constituindo indivíduos, profissionais da educação com relações às vezes precárias com os alunos, com a comunidade escolar e, muitas vezes, sob o olhar distante da gestão política. É lugar comum e fato facilmente verificável que a profissão de professor não é uma atividade devidamente valorizada, obrigando-o a ter duas ou mais atividades para compor uma renda mais digna. Mas é certo também que as relações de interdependência estabelecidas e conduzidas pelos agentes de uma comunidade escolar tanto podem levar a escola para a baixa produtividade, baixa autoestima, baixo autorrespeito e precárias relações afetuosas entre seus públicos, quanto potencializar um universo de reconhecimento totalmente distinto, como pudemos presenciar em algumas escolas. Há em curso um habitus desenrolando-se, inter-relações cada vez mais complexas, cuja obra de Elias nos auxilia a melhor compreendê-las.

\section{A desierarquizaÇão no Processo educativo}

Relacionando a vivência no projeto, os resultados e as ações, percebe-se que a desierarquização do processo educativo promove um ganho qualitativo na relação de ensino/ aprendizagem. Desse modo, continuar vendo a inter-relação professor-aluno do mesmo modo que sociedade-indivíduo, como elementos análogos, se revela um erro, pois professor e aluno estão sempre em um processo de interdependência, de forma que ambos aprendem e dialogam entre si. Além desse ponto, a escola também pode ser vista pela perspectiva reticular, ou seja, alunos e integrantes mostram o funcionamento da escola a partir das inter-relações, tornando mais compreensíveis os processos de complexificação, que dizem respeito às constantes mudanças em sua configuração. Desse modo, a estrutura da escola passa a ser vista de forma dinâmica, dialógica e horizontal, e não mais de forma rígida, hierárquica e verticalizada. Portanto, se a escola for pensada desse modo, professor e aluno passam a ter outra importância, pois os pontos que não eram percebidos passam a ser valorizados. Todos começam a ser ouvidos e não mais reprimidos por uma estrutura de poder e hierarquia.

Outro elemento que cabe discutir é a questão reticular do conhecimento. O conhecimento não é apenas construído na sala de aula, mas na vida do aluno, dentro da escola, fora da escola, na sua comunidade, com a sua família, com os seus amigos, com as mídias e redes sociais. Assim, pensar no processo de ensino/aprendizagem para além da sala de aula também é fundamental. Como discutido durante o trabalho, a sociologia de Norbert Elias 
fornece bases importantes para se pensar a educação e o conhecimento, de forma interdependente e em constante mudança, mostrando a importância das inter-relações travadas no interior do sistema educacional. Em resumo, quanto maior o nível de reconhecimento e colaboração mútua, menor o número de conflitos e tanto mais satisfatórios os resultados do processo educacional, alterando assim a dinâmica das relações de interdependência, tornando-as mais sensíveis e compreensíveis aos seus habitus e transformações.

\section{REFERÊNCIAS}

ELIAS, Norbert. A Sociedade dos Indivíduos. Organização: Michael Schröter. Tradução: Vera Ribeiro. Rio de Janeiro: J. Zahar, Brasil, 1994.

. Mozart: sociologia de um gênio. Rio de Janeiro: Jorge Zahar Ed., 1995.

. O Processo Civilizador. Uma História dos Costumes, v. I. Rio de Janeiro: J. Zahar, 2011.

. O Processo Civilizador. Formação do Estado e Civilização, v. 2. Rio de Janeiro: J. Zahar, 1993.

. Os Alemães: A luta pelo poder e a evolução do habitus nos séculos XIX e XX. Rio de Janeiro: Zahar, 1997.

. Sociología Fundamental. Traducción: Gustavo Muñoz. Barcelona: Gedisa, 2008.

FREUD, Sigmund. $\mathbf{O}$ futuro de uma ilusão. Tradução: Renato Zwick. Revisão Técnica e Prefácio: Renata Udler Cromberg. Porto Alegre: L\&PM, 2015.

. O Mal-estar na civilização. In: FREUD, Sigmund. Obras Completas. Tradução: Paulo Cézar de Souza. São Paulo: Cia. das Letras, 2010.

FUHRMANN, Nadia. Luta por reconhecimento: reflexões sobre a teoria de Axel Honnet e as origens dos conflitos sociais. In: Barbarói, Santa Cruz do Sul, n. 38, jan./jun. 2013, p. 79-96. Acesso pelo endereço: https://online.unisc.br/seer/index.php/barbaroi/article/ view/2586. Último acesso em 14 de agosto de 2017.

GEERTZ, Clifford. A Interpretação das Culturas. Rio de Janeiro: Editora Guanabara, 1989.

HONNETH, Axel. O Eu no Nós. Reconhecimento como força motriz de grupos. In: Sociologias, ano 15, n. 33. Porto Alegre, mai./ago. 2013, p. 56-80. Disponível no endereço: http://www.scielo.br/pdf/soc/v15n33/v15n33a03.pdf. Último acesso em 15 de agosto de 2017.

HONNETH, Axel. Luta por Reconhecimento: a gramática moral dos conflitos sociais. São Paulo: Editora 34, 2009.

KIRSCHNER, Tereza. História e sociologia: a contribuição de Norbert Elias. Revista História e Cultura. Franca, v. 3, n. 3 (Especial), p. 53-65, dez. 2014. 
LEONTIEV, Alexis. O Desenvolvimento do Psiquismo, 2. ed. São Paulo: Centauro, 2004. LIBANIO, Deodato. O social, um lugar da técnica e da comunicação sob a perspectiva do continuum histórico, 135 páginas. Trabalho de conclusão de curso. Universidade Federal de Mato Grosso, Campus Cuiabá, defendida no dia 10 de abril de 2017.

MARX, Karl; ENGELS, Friedrich. A ideologia alemã. Tradução Álvaro Pina. São Paulo: E. Popular, 2009.

MOREIRA, Benedito Diélcio. Jovens e as Tecnologias: Entre a poética e o controle técnico. In: SOUSA, Carlos Ângelo de Meneses (Org.). Juventudes e Tecnologias: Sociabilidades e Aprendizagens. Brasília: Liber Livro, 2015, p. 21-41.

MOREIRA, Benedito Diélcio; FICHTNER, Bernd. Juventudes, tecnologias e consumo midiático: Andanças virtuais revelam a constituição do novo. Contemporânea, Revista de Comunicação e Cultura, Salvador, v. 13, n. 1, jan./abr. 2015, p. 67-83. Disponível em <http:// www.portalseer.ufba.br/index.php/contemporaneaposcom/article/view/13122/9583>. Acesso em 3 de julho de 2015.

SAAVEDRA, Giovani Agostini; SOBOTTKA, Emil Albert. Introdução à teoria de Axel Honneth. In: Civitas - revista de Ciências Sociais, v. 8, n. 1, jan./abr. 2008. Disponível no seguinte endereço: http://revistaseletronicas.pucrs.br/ojs/index.php/civitas/article/ view/4319. Último acesso em 15 de agosto de 2017.

VYGOTSKI, Lev Semenovich. A Construção do Pensamento e da Linguagem. São Paulo: Martins Fontes, 2001.

VYGOTSKI, Lev Semenovich. A Formação Social da Mente: o desenvolvimento dos processos psicológicos superiores. São Paulo: Martins Fontes, 2002.

\section{DAdos dos AUTORES}

\section{Benedito Dielcio Moreira}

Doutor em Educação pela Universität Siegen, Alemanha. Docente do Programa de Pós-Graduação em Cultura Contemporânea da Universidade Federal de Mato Grosso. Cuiabá/ MT - Brasil. dielcio.moreira@gmail.com

\section{Deodato Rafael Libânio De Paula}

Graduado em Comunicação Social (Jornalismo) pela Universidade Federal de Mato Grosso. Cuiabá/MT-Brasil. deodatorafaelji@gmail.com

Submetido em: 20-8-2017

Aceito em: 1-11-2017 